\title{
Fused 3-dimensional whole-heart coronary artery, coronary vein and myocardial scar imaging at 3 T: Feasibility in patients with ischemic and non-ischemic cardiomyopathy
} James A White*1, Nowell Fine², Lorne Gula², Raymond Yee², Mohammed AlAdmawi $^{2}$, Anna MacDonald ${ }^{2}$, Qi Zhang 3 , Terry Peters ${ }^{3}$ and Maria Drangova ${ }^{3}$

\author{
Address: ${ }^{1}$ London Health Sciences Centre/Robarts Research Institute/Lawson Health Research Institute, London, ON, Canada, ${ }^{2}$ London Health \\ Sciences Centre, London, ON, Canada and ${ }^{3}$ Robarts Research Institute, London, ON, Canada \\ * Corresponding author
}

from I3th Annual SCMR Scientific Sessions

Phoenix, AZ, USA. 21-24 January 2010

Published: 21 January 2010

Journal of Cardiovascular Magnetic Resonance 2010, I2(Suppl I):O35 doi:I0.I I86/I532-429X-I2-SI-O35

This abstract is available from: http://jcmr-online.com/content/I2/SI/O35

(C) 2010 White et al; licensee BioMed Central Ltd.

\section{Background}

Patients with cardiomyopathy are frequently considered for vascular-based interventions aimed at improving systolic performance. Cardiac Resynchronization Therapy (CRT) and Coronary Artery Revascularization (CAR) are dependent upon the presence of appropriate vascular targets and health of related myocardium for clinical success. A combined evaluation of coronary vascular targets and myocardial scar may benefit the planning of such procedures.

\section{Methods}

53 consecutive patients were enrolled prior to device (ICD and/or CRT) therapy $(\mathrm{N}=42)$ or CAR $(\mathrm{N}=11)$. All patients had imaging performed using a 3.0 Tesla MRI scanner. A cardiac-gated, 3-D whole-heart inversionrecovery gradient echo pulse sequence with respiratory navigator was used to obtain both a contrast-enhanced coronary MRA $(0.2 \mathrm{mmol} / \mathrm{kg}$ gadolinium infusion at 0.3 $\mathrm{ml} / \mathrm{sec}$ ) followed in 25 minutes by a late enhancement (scar) dataset. Both datasets were obtained using an isotropic voxel resolution of $1.3 \times 1.3 \times 1.3 \mathrm{~mm}$. All coronary artery and coronary vein segments were evaluated by consensus opinion for vessel image quality using a standard visual scoring system (score 0 to 4 ). Contrast to noise (CNR) and signal to noise (SNR) measurements of the proximal coronary artery and vein segments and myocardial scar were performed. Spatially matched datasets were then fused using 3-D segmentation of myocardial scar with fusion to coronary MRA for volume rendered visualization Figure 1.

\section{Results}

The mean age was $56.6 \pm 14.5$ years. Combined coronary MRA and 3D scar imaging was successfully performed in $49(92 \%)$ patients. Of 588 proximal-mid coronary artery and coronary vein segments $570(97 \%)$ were scored as clinically evaluable. The mean quality score of the proximal-mid coronary artery segments and coronary vein segments was $3.1 \pm 0.9$ and $3.2 \pm 0.9$, respectively. The SNR and CNR scores were $57.3 \pm 35.3$ and $48.3 \pm 31.6$ respectively for the left main coronary artery. The respective vales for the right coronary artery was and $47.2 \pm 31.4$ and $38.2 \pm 28.1$, respectively for the right coronary artery. The mean quality score for myocardial scar imaging was 2.90 \pm 0.98 , with an SNR and CNR of $54.2 \pm 29.9$ and $49.4 \pm$ 29.3 respectively. Image fusion was successful in all patients with quality scores of 2 or greater.

\section{Conclusion}

This study demonstrates clinical feasibility of MRI to provide matched isotropic 3-D imaging of coronary anatomy and myocardial scar. This novel fusion technique has the potential to assist in the pre-procedural planning of vascular-based cardiac interventions where myocardial scar is relevant to clinical response. 


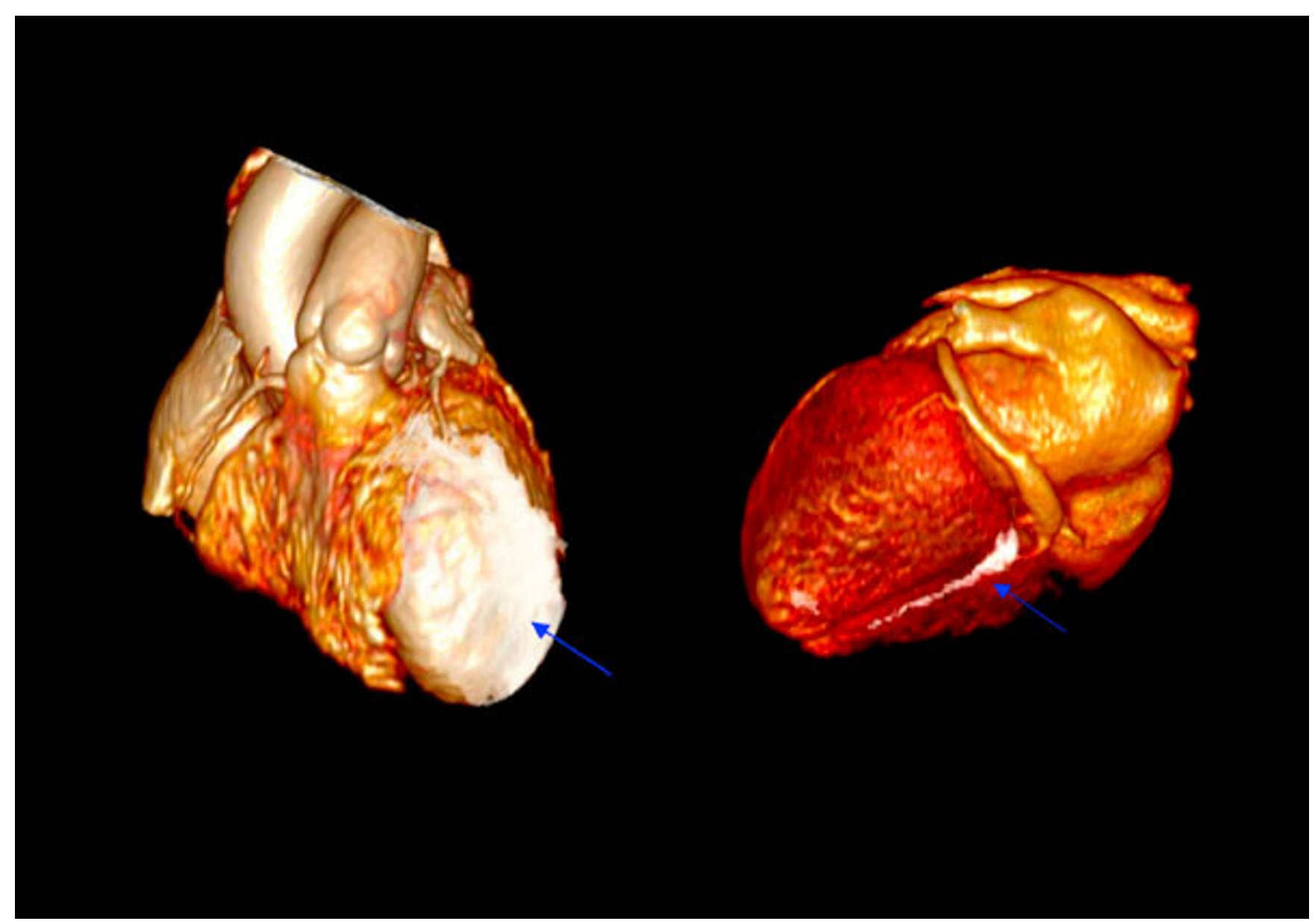

Figure I

Publish with BioMed Central and every scientist can read your work free of charge

"BioMed Central will be the most significant development for disseminating the results of biomedical research in our lifetime. " Sir Paul Nurse, Cancer Research UK

Your research papers will be:

- available free of charge to the entire biomedical community

- peer reviewed and published immediately upon acceptance

- cited in PubMed and archived on PubMed Central

- yours - you keep the copyright 